\title{
Cow-level risk factors for reproductive tract disease diagnosed by 2 methods in pasture-grazed dairy cattle in Ireland
}

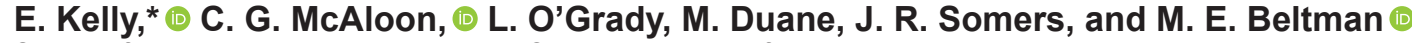 \\ School of Veterinary Medicine, University College Dublin, Belfield, Dublin 4, Ireland
}

\section{ABSTRACT}

The cow-side diagnosis of reproductive tract disease (RTD) involves identifying the presence of purulent vaginal discharge (PVD) and ultrasonographic endometritis (UE). The objectives of our study were to obtain prevalence estimates for RTD diagnosed by 2 methods (PVD and UE scoring) and to investigate the risk factors for increased probability of RTD if these methods are used in isolation or in combination. Our retrospective observational cohort study tested the hypothesis that RTD assessed by 2 methods would have similar risk factors, and that those would be mainly cow- and calving-related factors. We analyzed data from 5,049 pre-breeding examinations (PBE) from 2,460 spring-calved cows on 8 farms between 2014 and 2018. Cow-related details assessed were days in milk at PBE, breed, lactation number, dry period length, body condition score at calving and PBE, 305-d milk yield, predicted transmitting ability for production and fertility, the presence of a corpus luteum at PBE, and positive diagnosis the previous year. Calving details assessed were type of sire, calf sex, twinning, stillbirth, calving difficulty score, and retained fetal membranes. We conducted statistical analyses using 4 multivariable logistic regression models to identify the risk of RTD diagnosed by (1) PVD in isolation, (2) UE in isolation, (3) the presence of either PVD or UE; and (4) the presence of both PVD and UE. We accounted for herd, cow, and year as random effects in all 4 models. The overall prevalence of RTD in models $1,2,3$, and 4 were 7.5 , $6.7,11.6$, and $2.6 \%$, respectively. Days in milk at PBE, the interaction between days in milk and retained fetal membranes, twinning, and the predicted transmitting ability for calving interval were consistently significant risk factors for positive scores in all 4 models. Considerable calving difficulty [adjusted odds ratio (AOR) $=13.64]$, Holstein Friesian dam breed $(\mathrm{AOR}=2.58)$, first lactation $(\mathrm{AOR}=2.39)$, and body condition score

Received June 4, 2019.

Accepted September 19, 2019.

*Corresponding author: kellyemmet@gmail.com at $\mathrm{PBE}(\mathrm{AOR}=1.64)$ were risk factors for a positive PVD score but not for a positive UE score. Fifth lactation $(\mathrm{AOR}=1.69)$, a beef-sired calf $(\mathrm{AOR}=1.46)$, and the absence of a corpus luteum at PBE $(\mathrm{AOR}=1.57)$ were risk factors for a positive UE score but not for a positive PVD score. These results support the hypothesis that most of the risk factors for PVD and UE are the same but some are distinctly different, implying that in some instances the 2 methods diagnose separate components of the RTD complex.

Key words: dairy cow, purulent vaginal discharge, clinical endometritis, ultrasound, risk factor

\section{INTRODUCTION}

Microbial contamination of the uterine lumen occurs in 80 to $90 \%$ of dairy cattle in the first 2 weeks postpartum (Sheldon et al., 2006). Failure to clear pathogenic bacteria from the uterine lumen after 3 weeks postpartum results in endometritis (Gilbert et al., 2005; Sheldon et al., 2006). Endometritis causes endometrial tissue damage, and pathogen-associated molecules disrupt endocrine function (Sheldon et al., 2002; Williams et al., 2007; Herath et al., 2009). Affected cows can experience a delayed resumption of ovarian activity after calving and prolonged luteal phases once they do begin to cycle (Opsomer et al., 2000; Sheldon et al., 2002). Ultimately, endometritis has been shown in several studies to reduce submission, conception, and pregnancy rates, and to increase culling for failure to conceive (LeBlanc et al., 2002; McDougall et al., 2007, 2011; Šavc et al., 2016).

Clinical endometritis has been defined by the presence of purulent ( $>50 \%$ pus) vaginal discharge $21 \mathrm{~d}$ or more postpartum, or mucopurulent $(50 \%$ pus, $50 \%$ mucus) discharge $26 \mathrm{~d}$ postpartum without accompanied systemic signs (LeBlanc et al., 2002; Sheldon et al., 2009). Subclinical endometritis is diagnosed based on uterine cytology: more than $18 \%$ neutrophils in uterine cytology samples collected 21 to $33 \mathrm{~d}$ postpartum, or more than 10\% neutrophils at 34 to $47 \mathrm{~d}$ (Sheldon et al., 2006 ), in the absence of visible pus in the vagina. Cowside diagnosis of subclinical endometritis with uterine 
lavage or cytobrush cytology poses substantial practical challenges, including time constraints, laboratory processing, and expense, and it assesses only 1 element of reproductive tract inflammatory disease (Dubuc et al., 2010a; Deguillaume et al., 2012; de Boer et al., 2014). More recently, many authors have moved away from using the term clinical endometritis, preferring the term purulent vaginal discharge (PVD) because it is more descriptive and covers a range of conditions: endometritis, vaginitis, and cervicitis (Dubuc et al., 2010a; de Boer et al., 2014). However, the use of a Metricheck device (Simcro, Hamilton, New Zealand) in isolation fails to detect cows that have no vaginal discharge but evidence of ultrasonographic endometritis (UE; Savc et al., 2016). With the widespread use of ultrasonography in dairy reproduction, ultrasonographic scoring systems for assessing endometritis have been studied and shown to be both practical and effective at diagnosing both clinical and subclinical endometritis and predicting reproductive outcomes in cows (Mee et al., 2009; LópezHelguera et al., 2012; Meira et al., 2012). Dubuc et al. (2010a) found that cows diagnosed with PVD or subclinical endometritis at 35 DIM had poorer subsequent reproductive performance than unaffected cows, and these effects were additive if both conditions occurred simultaneously. More recently, Šavc et al. (2016) found that a combination of both vaginal mucus scoring and ultrasonography of the uterine tract was better at predicting fertility outcomes than either method used in isolation. Because poorer fertility outcome is predicted by both methods of diagnosis, and because both methods assess different parts of the reproductive tract, we will use the broader term "reproductive tract disease" (RTD) to describe both PVD and UE in this report, because it is a more all-encompassing and descriptive term than previous terms such as clinical endometritis.

Globally, the incidence of RTD in dairy cows varies widely, from 5 to $30 \%$. This variation is due to the aforementioned issues around definitions, disease states, timing of examination relative to calving, lack of a gold standard diagnostics, and differences between populations and farming systems (de Boer et al., 2014). Many risk factors for PVD are well established, including DIM at examination, retained fetal membranes (RFM), metritis, dystocia, abortion, stillbirth, twinning, male offspring, negative energy balance, and primiparity (Ghanem et al., 2002; Kim and Kang, 2003; McDougall et al., 2007; Dubuc et al., 2010b; Potter et al., 2010; Giuliodori et al., 2013, 2017). However, of the few studies in which endometritis was diagnosed by ultrasound tract scoring, risk factors identified have been DIM at examination, primiparity, dystocia, and cows with inferior genetic merit for traditional fertility traits (Carthy et al., 2014, 2016; Fitzgerald et al., 2014).
Given that both PVD and UE affect subsequent reproductive performance (Mee et al., 2009; Dubuc et al., 2010a; Šavc et al., 2016) and most studies have focused only on establishing prevalence estimates and risk factors for RTD determined by a single diagnostic method (PVD, UE or subclinical endometritis), the objective of the present study was to establish prevalence estimates and risk factors for the 2 most common cow-side diagnostics, used in isolation or in combination.

In nonseasonal calving herds, pre-breeding examinations (PBE) take place before the end of the voluntary waiting period; in seasonal calving herds, PBE take place before the mating start date, or just afterward in a small proportion of later-calving cows (Mee et al., 2009). Investigation of the risk factors for the different diagnostic methods for RTD will improve our understanding of those risk factors, helping to implement better herd-level monitoring and preventative measures, and helping to identify at-risk cows in seasonal calving systems for early intervention and treatment (McDougall et al., 2001). We hypothesized that RTD as assessed by Metricheck and ultrasound would have similar risk factors, and that these risk factors would be primarily cow and calving-related factors.

\section{MATERIALS AND METHODS}

\section{Animals and Herds}

This retrospective observational cohort study analyzed 5,049 PBE from 2,460 spring-calving cows in 8 commercial herds across 5 years (2014-2018). Cows were from convenience herds in an ongoing herd health management program that included routine reproductive pre-breeding checks conducted by University College Dublin and thus had reliable data recording. All selected herds were based in Co. Kildare, Ireland $\left(52^{\circ} 60^{\prime} \mathrm{N}, 6^{\circ} 50^{\prime} \mathrm{W}\right)$. Cow breeds in the herds were predominantly Holstein Friesian, Jersey, or Jersey crosses. Mean (standard deviation, SD) herd size was 126 (35), and mean parity was 2.88 (1.7). Cows were typically housed in freestall slatted sheds with cubicles during the winter (November to February), and were typically at pasture from mid-February until the end of October. During the winter, lactating cows received a mixed diet consisting of grass and maize silage with concentrate supplementation in the parlor. Turnout to pasture for lactating cows was typically in mid to late February, when the main component of their diet was grass supplemented with concentrates in the parlor. Cows were milked twice per day. The mean 305-d predicted milk yield was $6,428 \mathrm{~L} / \mathrm{cow}$ (SD 1,204 L). The criteria used for inclusion of cows were as follows: calving between January and May of any given year from 2014 
Table 1. Ultrasound classification of uterine tract scores (UTS) modified from Mee at al. (2009)

\begin{tabular}{ll}
\hline UTS & Uterine characteristic \\
\hline 0 & No fluid and a spoke-wheel-shaped lumen completely involuted with infolding of the endometrium \\
1 & No fluid or a small volume $(\leq 0.2 \mathrm{~cm})$ of intraluminal fluid in a spoke-wheel-shaped lumen with infolding of the endometrium \\
2 & $\begin{array}{l}\text { Small volume }(>0.2 \text { to }<0.5 \mathrm{~cm}) \text { of fluid of mixed echogenicity (gray or white) in a spoke-wheel-shaped lumen with infolding of } \\
\text { the endometrium and enlarged or stellate center }\end{array}$ \\
& $\begin{array}{l}\text { Moderate volume }(\geq 0.5 \mathrm{~cm}) \text { of fluid of mixed echogenicity (gray or white) in a spoke-wheel-shaped lumen with enlarged or } \\
\text { stellate center }\end{array}$ \\
& $\begin{array}{l}\text { Large volume }(\geq 1 \mathrm{~cm}) \text { of fluid of mixed echogenicity (gray or white) with hyperechoic particles in a circular lumen without } \\
\text { infolding of the endometrium }\end{array}$ \\
\hline
\end{tabular}

to 2018; had their first PBE conducted at 25 DIM or more; and were assessed and assigned scores using both Metricheck and ultrasonography. The PBE conducted on these cows were part of established routine fertility management on these farms. Cows were excluded from logistic regression analysis if they did not have adequate records of the appropriate selected risk factors.

\section{Clinical Examination}

As is typical of seasonal calving, pasture-based dairy systems, the majority of PBE took place before the mating start date in eligible cows (i.e., more than $25 \mathrm{~d}$ calved) and after the mating start in later-calving cows, once they became eligible. Examinations took place in March, April, May, and June each year. Each cow received 1 PBE by 1 of 3 members of the University College Dublin Health Herd Group. Examinations were conducted between 25 and 86 DIM (median 49 DIM). On the day of the PBE, all cows were identified and their BCS assigned using a 5-point system (0.25-unit increments; $1=$ emaciated and $5=$ obese; Edmonson et al., 1989). The perineal area of each cow was cleaned with paper towel, after which vaginal mucus samples were taken using a Metricheck device as described by McDougall et al. (2007). Samples were assigned a mucus score on a scale of 0 to 3 as follows: MS0 = no or clear mucus; MS1 = clear mucus with flecks of purulent material; MS2 $=$ mucopurulent material $\leq 50 \%$ white mucopurulent material, not fetid; MS3 $=\geq 50 \%$ purulent material or any fetid discharge (Williams et al., 2005). We defined MS2 and MS3 as positive for PVD based on previously published work (LeBlanc et al., 2002; Sheldon et al., 2006; Dubuc et al., 2010a; Šavc et al., 2016). The Metricheck device was cleaned and disinfected between cows by rinsing it in a very mild chlorhexidine solution.

Immediately after the Metricheck assessment, all cows received a transrectal reproductive examination using an ultrasound scanner (Easi-Scan 1, 7.5-MHz linear-array transducer; BCF Technology, Mitcham, Australia). Both ovaries were examined for the presence or absence of a corpus luteum. Uterine content was scored on a scale of 0 to 4 using a modified scale based on Mee et al. (2009) and used previously by our research group (Šavc et al., 2016) and others (Carthy et al., 2014, 2016); the scale is described in Table 1. Uterine tract scores $\geq 2$ were considered positive for UE, based on previously published work (Barlund et al., 2008; Mee et al., 2009; Šavc et al., 2016). All participating members received formal instructions to standardize the procedures above.

For ethical and animal welfare reasons, all cows with positive mucus or uterine tract score were recommended to be treated with closprostenol (Estrumate, $500 \mu \mathrm{g}$ IM; MSD Ireland, Dublin, Ireland) if a corpus luteum was present, followed by cephapirin (Metricure, $500 \mathrm{mg}$ intrauterine suspension; MSD Ireland) $72 \mathrm{~h}$ later; and those without a corpus luteum were recommended to be treated with cephapirin only.

For the first 6 wk of each breeding season, all animals detected in standing estrus were bred using AI with frozen-thawed semen from bulls of proven fertility. Thereafter, stock bulls were used for breeding (for approximately 6-9 wk). All cows were examined at least $30 \mathrm{~d}$ post-service to determine pregnancy status and again after $60 \mathrm{~d}$ post-service for final confirmation of pregnancy.

\section{Calving and Fertility Data}

Calving and fertility data were recorded by farmers and entered into an on-farm software package (Irish Farm Computers, www.agrinet.ie). Information available on the cows included the following: date of birth; parity; dry-off dates; and predicted 305-d milk yield, fat, and protein $(\mathrm{kg})$. We extrapolated 305 -d yields using milk recording available at the end of lactation from each cow, obtained from the Irish Cattle Breeding Federation (www.icbf.ie). Predicted transmitting abilities 
for milk ( $\mathrm{kg}$ of fat and protein) and fertility (calving interval and survival) were also obtained from the Irish Cattle Breeding Federation, and were updated several times per year using information on daughter performance data for all sires. The breeding values for a given animal are composed predominantly of the genetic values of the cow's sire and maternal grandsire, and were based on the latest assessment conducted on March 21, 2019 , for all cows. Information available on the calving period was as follows: date of calving, BCS at calving, calving assistance score using a scale of 1 to $4(1=$ normal; 2 = some assistance; $3=$ considerable difficulty; $4=$ veterinary assistance), stillbirth (dead within $24 \mathrm{~h}$ of calving), twins, calf sex, calf sire, and RFM (failure to pass fetal membranes by $24 \mathrm{~h}$ after calving). Other than RFM, postpartum disease information was not recorded in a standardized or consistent manner across farms and was deemed ineligible for analysis. Information on breeding included AI dates, sire, AI operator, and pregnancy test results.

\section{Statistical Analysis}

We carried out all data manipulation and analyses using the $\mathrm{R}$ statistical programming language ( $\mathrm{R}$ Core Team, 2015). We calculated the prevalence of PVD in isolation, UE in isolation, either PVD or UE, and both PVD and UE, as a proportion of positive cows (mucus score or uterine tract score $\geq 2$, or both) over the total cows recruited. A total of 4,952 PBE from 2,419 cows were included in the model-building process, because some examinations were missing BCS measures (47 exams; 9 cows), and some cows had no reliable PTA data available (56 exams; 32 cows) and were therefore censored. We considered PVD in isolation (model 1), UE in isolation (model 2), either PVD or UE (model 3), and both PVD and UE (model 4) as outcomes for 4 separate logistic regression models (Figure 1). The categorical risk factors tested were as follows: lactation number ( 1 to $\geq 5$ ); breed [coded as Holstein Friesian, $>11 / 16)$, Jersey $(>11 / 16)$, or crossbred $(>85 \%$ of which were Jersey cross)]; dry period length in days $(<60,60-90$ and $>90)$; calf sex; RFM; twins; stillbirth; sire type (dairy or beef and AI or stock bull); BCS at calving (thin $<3$; ideal $3-3.25$; fat $\geq 3.5$ ), BCS at PBE (thin $<2.75$; ideal 2.75-3.25; fat $\geq 3.5$ ); the presence of a corpus luteum at PBE; and positive RTD diagnosis by either method on the PBE of the previous year. Given the low numbers of calving scored as a 3 or 4, we merged these levels. Continuous risk factors tested were as follows: DIM at PBE; milk production (305-d milk predicted yield in kilograms and 305-d milk predicted yield of fat and protein); and genetic merit indices for production (PTA for milk in kilograms; PTA for milk

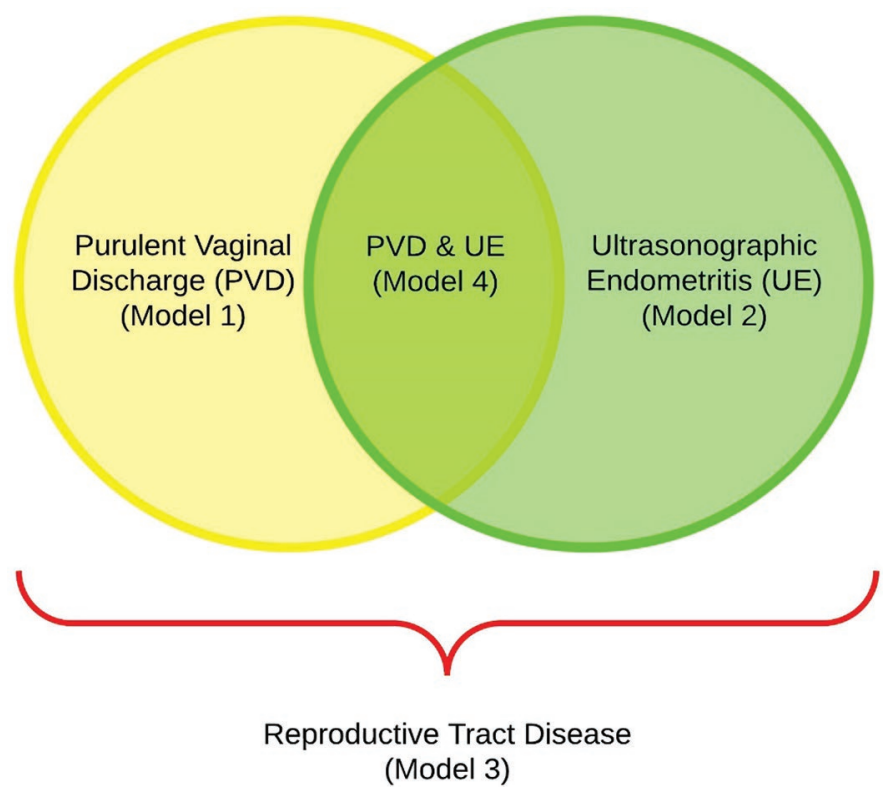

Figure 1. Venn diagram outlining the risk factor models used in the present study.

fat; PTA for milk protein) and fertility (PTA for calving interval and PTA for survival). All continuous covariates were standardized by subtracting the observation value from the mean and then dividing by the standard deviation. All standardized continuous covariates were then tested as linear and quadratic covariates.

We initially investigated individual explanatory covariates in a univariate logistic regression framework and carried them forward for multivariable regression analysis ("glmer" function in "lme4" Package; R Core Team (2015)] when $P<0.2$. All candidate covariates for multivariable modeling were assessed for correlation. When 2 variables were highly correlated $(>0.8), 1$ was selected and brought forward for multivariable analysis based on the variable that resulted in the model with the lowest Akaike information criterion. Variables dropped due to collinearity were replaced in the final model to test for significance. We constructed the model using forward stepwise elimination, and variables with a significance probability of $P<0.05$ were retained in the model. Herd, cow, and year were treated as random effects, because sampling was clustered within herd and year, and cow-level risk factors in the general Irish grazing populations were what was of interest. All 2 -way interactions were assessed and retained in the model if $P<0.05$. The models produced adjusted odds ratios (AOR), which served as an approximation of the association between risk factors and RTD.

We visualized interactions in the models by predicting the probabilities from the multivariable analysis for the variables of interest, holding all other variables at 


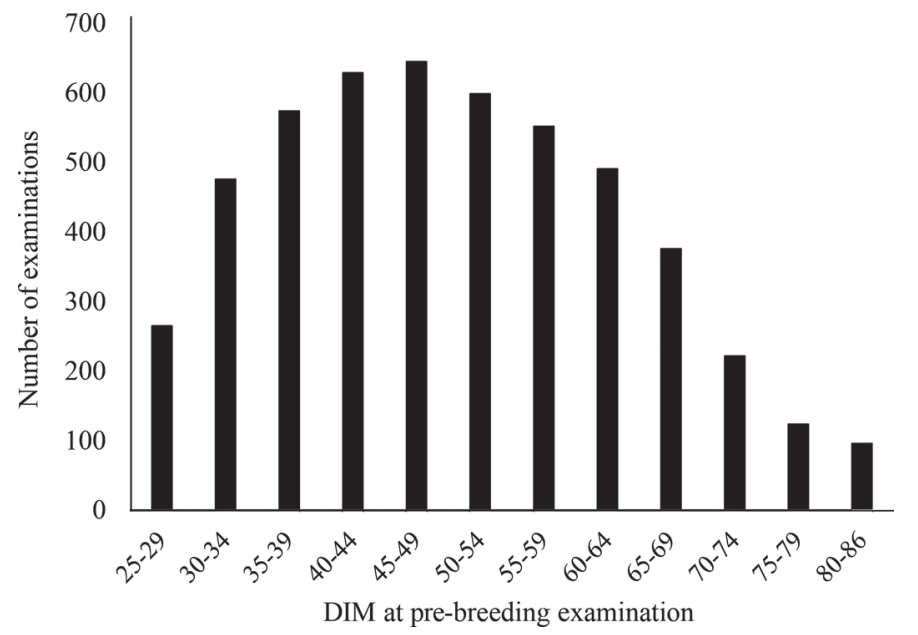

Figure 2. Histogram of DIM at pre-breeding examination.

the referent and mean of the population. When the interactions were between continuous and categorical variables, we plotted out their predicted probabilities graphically for ease of interpretation; some are displayed for illustrative purposes (Supplemental Figures S1 and S2; https://doi.org/10.3168/jds.2019-17064). Finally, post hoc power simulations were conducted to frame the interpretations made from our study especially with regards of nonsignificant variables.

\section{RESULTS}

\section{Descriptive Statistics}

In total, we analyzed 5,049 PBE on 2,460 springcalving cows from 8 farms, conducted each spring period over 5 yr. The approximate mean date of calving each year was February 18, and the mean DIM at PBE was $50 \mathrm{~d}$, corresponding to a mean date of examination of April 9, approximately $3 \mathrm{wk}$ before the typical mating start date of the herds of May 1 . We found a positively skewed distribution of DIM at first examination, summarized in Figure 2. The incidences of assisted calvings, RFM, stillbirth, and twins were 10.5, 1.8, 3.9, and $2.0 \%$, respectively. The distribution of mucus score and uterine tract score for all examinations is outlined in Figure 3. The prevalence of RTD differed according to the diagnostic method used, and in each of the 4 models: PVD in isolation, UE in isolation, PVD or UE, and PVD and UE were 7.5, 6.7, 11.6, and 2.6\%, respectively (Table 2). Only $35 \%(132 / 380)$ of cows defined as having PVD (mucus score $\geq 2$ ) had uterine tract score $\geq 2$, and only $39 \%(132 / 339)$ of cows defined as having UE (UTS $\geq 2$ ) had mucus score $\geq 2$. The prevalence of RTD as defined by any method was higher in the earlier DIM at examination and is outlined in Table 2.

\section{Model Outcomes}

The final multivariable models are presented in Tables 3 to 6 and were conducted on a total of 4,952 PBE from 2,419 cows after censoring. For the multivariable analysis, only non-collinear significant factors $(P<0.2)$ were carried forward in each model. For the majority of variables, the reference category was chosen to avoid negative coefficients and odds ratios below 1 . Regression coefficients and odds ratios are quoted for standardized continuous variables and their interactions, as outlined in Tables 3 to 6 .

\section{Risk Factors for PVD (Model 1)}

The outputs from the final multivariable logistic regression for model 1 are presented in Table 3. The

\begin{tabular}{ccccccc}
\hline & & & & & & Total \\
& UTS0 & UTS1 & UTS2 & UTS3 & UTS4 & $\begin{array}{c}\text { mucus } \\
\text { score }\end{array}$ \\
\hline MS0 & 3,565 & 482 & $93^{3}$ & $47^{3}$ & $14^{3}$ & 4,201 \\
MS1 & 284 & 131 & $25^{3}$ & $22^{3}$ & $6^{3}$ & 468 \\
MS2 & $92^{3}$ & $54^{3}$ & $31^{3,4}$ & $11^{3,4}$ & $14^{3,4}$ & $202^{1}$ \\
MS3 & $57^{3}$ & $45^{3}$ & $18^{3,4}$ & $18^{3,4}$ & $40^{3,4}$ & $178^{1}$ \\
\hline Total UTS & 3,998 & 712 & $167^{2}$ & $98^{2}$ & $74^{2}$ & 5,049 \\
\hline
\end{tabular}

Figure 3. Mucus score (MS0 to MS3) and uterine tract score (UTS0 to UTS4) results for all pre-breeding examinations $(\mathrm{n}=5,049)$ in the study before censoring. Each cell represents the number of pre-breeding examinations with each score. Exams in yellow $=$ positive examinations used in the purulent vaginal discharge (PVD) model; exams in green = positive examinations used in the ultrasonographic endometritis (UE) model; exams in blue and orange = positive examinations in the PVD or UE models; exams in orange = positive examinations in the PVD and UE models. 
Table 2. Prevalence of reproductive tract disease diagnosed by 2 methods [Metricheck (Simcro, Hamilton, New Zealand) and ultrasound] used in isolation and in combination and categorized by DIM ( $\mathrm{n}=5,049$ examinations)

\begin{tabular}{lcccc}
\hline & \multicolumn{4}{c}{ Prevalence, ${ }^{1} \%$ (no. positive) } \\
\cline { 2 - 5 } $\begin{array}{l}\text { DIM at pre-breeding } \\
\text { examination (no. of cows) }\end{array}$ & PVD & UE & PVD or UE & PVD and UE \\
\hline $25-49(2,589)$ & $9.8(253)$ & $8.7(224)$ & $14.9(387)$ & $3.5(90)$ \\
$50-74(2,239)$ & $5.2(117)$ & $4.7(105)$ & $8.1(182)$ & $1.8(40)$ \\
$\geq 75(221)$ & $4.5(10)$ & $4.5(10)$ & $8.1(18)$ & $0.9(2)$ \\
Total $(5,049)$ & $7.5(380)$ & $6.7(339)$ & $11.6(587)$ & $2.6(132)$ \\
\hline
\end{tabular}

${ }^{1} \mathrm{PVD}=$ purulent vaginal discharge (positive $=$ mucus score $\geq 2$; mucopurulent); UE $=$ ultrasonographic endometritis (positive $=$ uterine tract score $\geq 2 ;>0.2 \mathrm{~cm}$ intrauterine fluid).

probability of PVD decreased with each day postpartum that the examination took place $(P<0.01)$. Cow factors that increased the odds of PVD were primiparity (first lactation; $P<0.01$ ), Holstein Friesian breed $(P<0.01)$, having a BCS of less than 2.75 at the PBE $(P<0.05)$, and having an inferior PTA for calving interval $(P<0.05)$. Calving factors that increased the odds of PVD were giving birth to twins $(P<0.01)$ and having a calving difficulty score of $\geq 3(P<0.01)$. We found an interaction $(P<0.01)$ between dam breed and calving difficulty score, indicating that if a Jersey cow had considerable calving difficulty (score $\geq 3$ ), she had a higher probability (predicted probability $=0.192$ ) of PVD than a Holstein Friesian cow experiencing considerable calving difficulty (predicted probability $=$
0.065). We found an interaction $(P<0.05)$ between RFM and DIM at examination. The probability of PVD was increased if a cow with RFM was examined earlier postpartum, but this effect diminished with increasing DIM, eventually converging at approximately 55 DIM, as shown in Supplemental Figure S1 (https://doi.org/ 10.3168/jds.2019-17064).

\section{Risk Factors for UE (Model 2)}

The outputs from the final multivariable logistic regression for model 2 are presented in Table 4. The probability of UE decreased with each day postpartum that the examination took place $(P<0.01)$. Cow factors that increased the odds of UE were multiparity

Table 3. Results from the final multivariable logistic regression (model 1) used to identify cow-level risk factors for purulent vaginal discharge (PVD)-positive cows (mucus score $\geq 2$ )

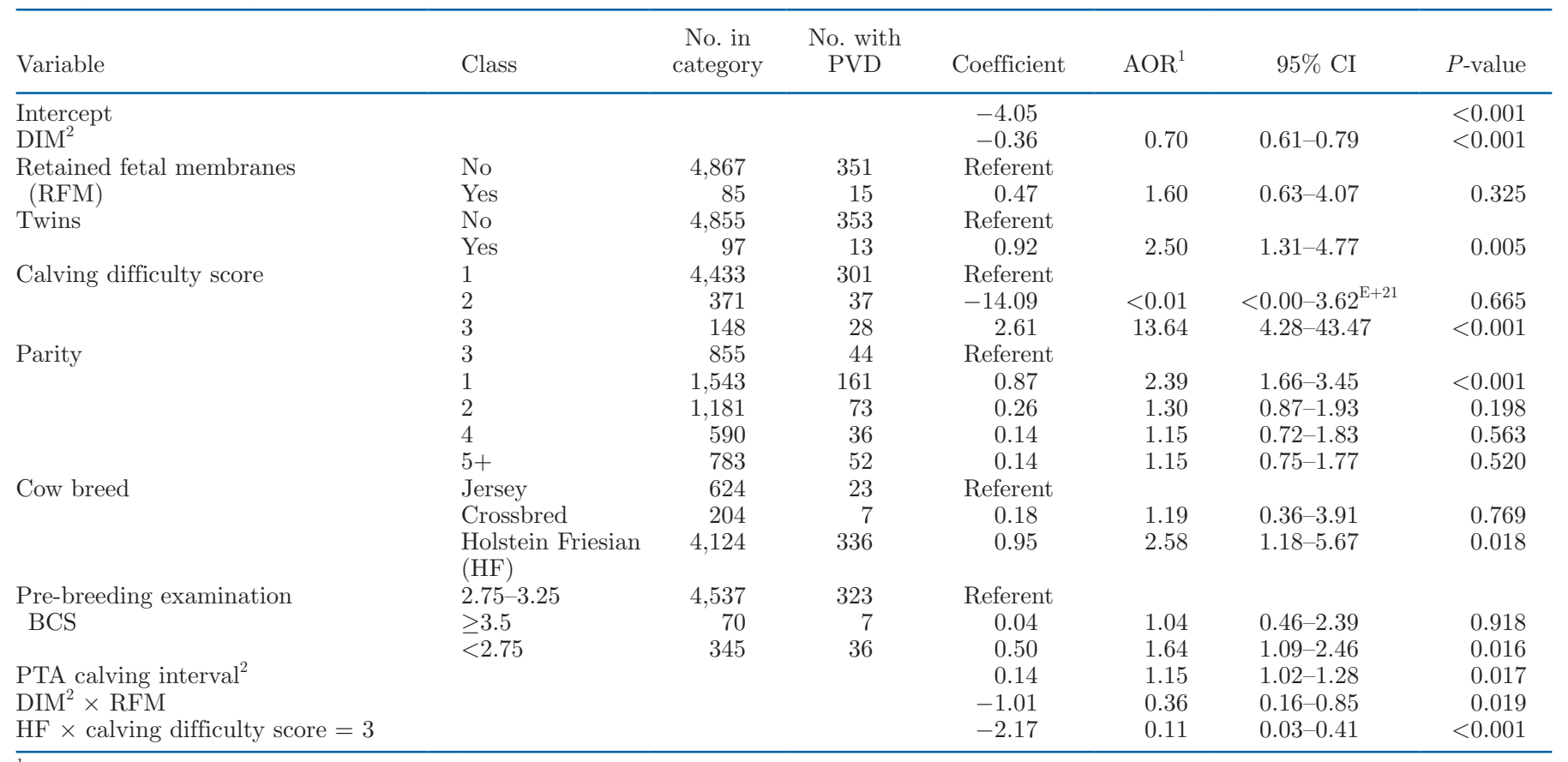

${ }^{1} \mathrm{AOR}=$ adjusted odds ratio.

${ }^{2}$ Regression coefficients and odds ratios are for standardized continuous variables. 
( $\geq$ fifth lactation; $P<0.01$ ), having an inferior PTA for calving interval $(P<0.01)$, and the absence of a corpus luteum at the PBE $(P<0.01)$. Calving factors that increased the odds of UE were giving birth to twins $(P<$ $0.01)$ and giving birth to a calf sired by a beef breed $(P$ $<0.05)$. We found an interaction $(P<0.01)$ between the presence of a corpus luteum on an ovary and DIM at examination. This interaction indicates that the probability of UE was higher when cows were examined earlier in milk if they had a corpus luteum present than if they did not, but the probability was much greater if a corpus luteum was not present and they were examined later in milk (Supplemental Figure S2; https:/ /doi.org/10.3168/jds.2019-17064). Again, we found an interaction $(P<0.01)$ between cows with RFM and DIM at examination, illustrating that the probability of UE was greater in cows with RFM when examined earlier in lactation, but the probability diminished with time, eventually converging at approximately 44 DIM (similar pattern to that in Supplemental Figure S1).

\section{Risk Factors for PVD or UE (Model 3)}

The outputs from the final multivariable logistic regression for model 3 are presented in Table 5. The probability of PVD or UE decreased with each day postpartum that the examination took place $(P<$ 0.01). Cow factors that increased the odds of PVD or UE were first and fifth lactation $(P<0.01)$, Holstein Friesian breed $(P<0.05)$, having an inferior PTA for calving interval $(P<0.01)$, and the absence of a corpus luteum at the $\operatorname{PBE}(P<0.01)$. Calving factors that increased the odds of PVD or UE were giving birth to twins $(P<0.05)$ and having a calving difficulty score of $\geq 3(P<0.01)$. We found an interaction $(P<$ 0.01 ) between dam breed and calving difficulty score, indicating that if a Jersey cow had considerable calving difficulty (score $\geq 3$ ), she had a higher probability (predicted probability $=0.212$ ) of PVD or UE than a Holstein Friesian cow experiencing considerable calving difficulty (predicted probability $=0.096$ ). We found an interaction $(P<0.01)$ between the presence of a corpus luteum on an ovary and DIM at examination, as seen in model 2. This interaction again indicated that the probability of PVD or UE was higher when cows were examined earlier in milk if they had a corpus luteum present than if they did not, but the probability was much greater if a corpus luteum was not present and they were examined later in milk (Supplemental Figure S2; https://doi.org/10.3168/jds.2019-17064). Again, we found an interaction $(P<0.01)$ between cows with RFM and DIM at examination, illustrating that the probability of PVD or UE is greater in cows with RFM when examined earlier in lactation, but the probability diminished with time, eventually converging at approximately 53 DIM (similar pattern to the one seen in Supplemental Figure S1).

\section{Risk Factors for Both PVD and UE (Model 4)}

The outputs from the final multivariable logistic regression for model 4 are presented in Table 6 . The probability of PVD and UE decreased with each day postpartum that the examination took place $(P<$

Table 4. Results from the final multivariable logistic regression (model 2) used to identify cow-level risk factors for ultrasonographic endometritis (UE)-positive cows (uterine tract score $\geq 2$ )

\begin{tabular}{|c|c|c|c|c|c|c|c|}
\hline Variable & Class & $\begin{array}{l}\text { No. in } \\
\text { category }\end{array}$ & $\begin{array}{l}\text { No. with } \\
\text { UE }\end{array}$ & Coefficient & $\mathrm{AOR}^{1}$ & $95 \% \mathrm{CI}$ & $P$-value \\
\hline Intercept & & & & -3.13 & & & $<0.001$ \\
\hline $\mathrm{DIM}^{2}$ & & & & -0.50 & 0.60 & $0.51-072$ & $<0.001$ \\
\hline \multirow{3}{*}{$\begin{array}{l}(\mathrm{RFM}) \\
\text { Twins }\end{array}$} & Yes & 85 & 13 & -1.09 & 0.34 & $0.04-2.82$ & 0.315 \\
\hline & No & 4,855 & 319 & Referent & & & \\
\hline & Yes & 97 & 13 & 0.93 & 2.53 & $1.33-4.80$ & 0.005 \\
\hline \multirow{3}{*}{ Parity } & 2 & 1,181 & 61 & -0.13 & 0.88 & $0.54-1.31$ & 0.526 \\
\hline & 4 & 590 & 39 & 0.08 & 1.09 & $0.69-1.70$ & 0.719 \\
\hline & $5+$ & 783 & 79 & 0.52 & 1.69 & $1.14-2.48$ & 0.008 \\
\hline \multirow{2}{*}{ Sire breed } & Dairy & 4,282 & 263 & Referent & & & \\
\hline & Beef & 670 & 69 & 0.38 & 1.46 & $1.05-2.02$ & 0.022 \\
\hline \multirow[t]{2}{*}{ Corpus luteum present } & Yes & 3,641 & 240 & Referent & & & \\
\hline & No & 1,311 & 126 & 0.45 & 1.57 & $1.22-2.05$ & $<0.001$ \\
\hline
\end{tabular}


Table 5. Results from the final multivariable logistic regression (model 3) used to identify cow-level risk factors for purulent vaginal discharge (PVD)- or ultrasonographic endometritis (UE)-positive cows (mucus score $\geq 2$ or uterine tract score $\geq 2$ )

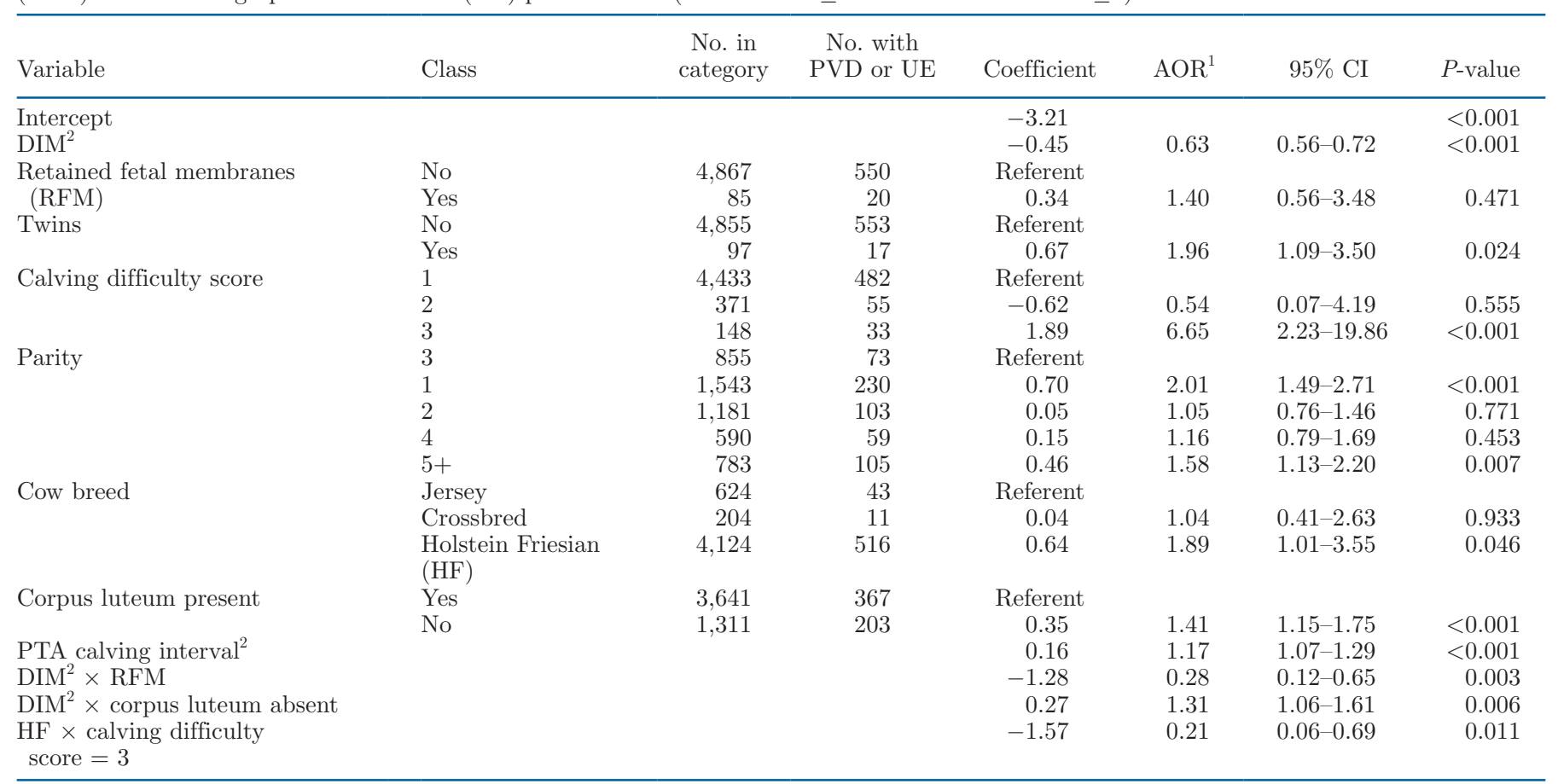

${ }^{1} \mathrm{AOR}=$ adjusted odds ratio.

${ }^{2}$ Regression coefficients and odds ratios are for standardized continuous variables.

0.01). The cow factor that increased the odds of PVD and UE was having an inferior PTA for calving interval $(P<0.05)$. The calving factor that increased the odds of PVD or UE was giving birth to twins $(P<0.01)$. Again, we found an interaction $(P<0.05)$ between cows with RFM and DIM at examination, illustrating that the probability of PVD or UE is greater in cows with RFM when examined earlier in lactation, but the probability diminished with time, eventually converging at approximately 42 DIM (similar pattern to the one seen in Supplemental Figure S1; https://doi.org/10 $.3168 /$ jds.2019-17064).

\section{DISCUSSION}

The prevalence of PVD in this study was similar to others recently published on PVD in grazing dairy cows when a Metricheck device was used. Giuliodori et al. (2017), who studied the risk factors for PVD, reported a prevalence of $9.3 \%(213 / 2,303)$ vaginal discharge scores $\geq 2$ (on a scale of $0-3$ ) between 21 and 49 DIM. Similarly, McDougall et al. (2007) showed a prevalence of $9.3 \%(258 / 2,780)$ vaginal discharge scores $\geq 3$ (on a scale of $0-5)$ in cows examined $35 \mathrm{~d}$ before mating start date. These findings are broadly comparable to the $9.8 \%$

Table 6. Results from the final multivariable logistic regression (model 4) used to identify cow-level risk factors for purulent vaginal discharge (PVD)- and ultrasonographic endometritis (UE)-positive cows (mucus score $\geq 2$ and uterine tract score $\geq 2$ )

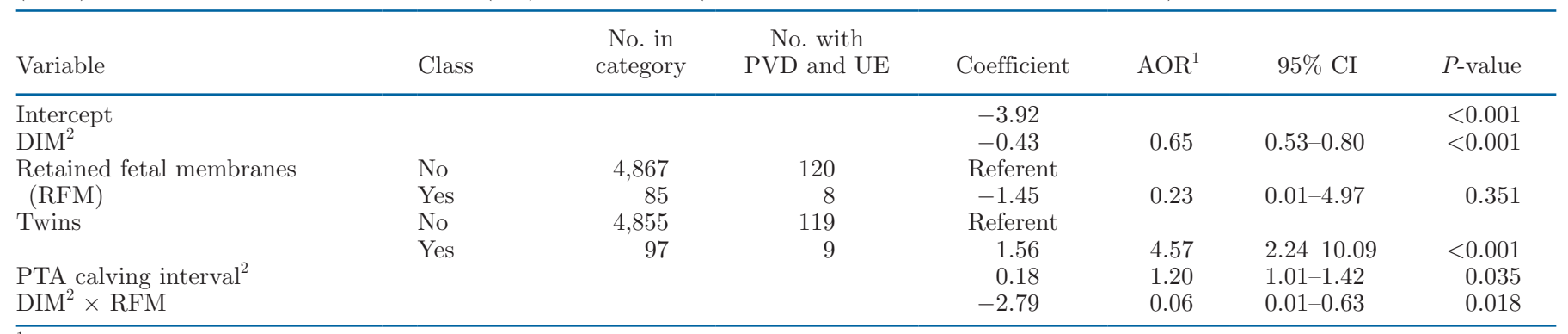

${ }^{1} \mathrm{AOR}=$ adjusted odds ratio.

${ }^{2}$ Regression coefficients and odds ratios are for standardized continuous variables. 
$(253 / 2,589)$ prevalence seen in the present study for PVD alone when cows were examined between 25 and 49 DIM. However, both of these authors included cows that had flecks of pus in clear mucus as positive PVD cases, based on their subsequent reduced reproductive performance compared with cows that had clear or no mucus. In the present study, a PVD case was defined as a cow with purulent or mucopurulent discharge, based on previous published work by this research group on a set of similar farms using the same scoring method, which indicated no significant difference between cows with flecks of pus or clear discharge (Šavc et al., 2016).

The prevalence of UE in this study was also similar to other published work. Barlund et al. (2008) showed a prevalence of $10 \%(22 / 221)$ endometritis when using a 90th percentile intrauterine fluid cutoff of $>3 \mathrm{~mm}$ in cows that were examined at 28 to 41 DIM, similar to the $8.7 \%(224 / 2,589)$ prevalence seen in the present study when cows were examined between 25 and 49 DIM using a cutoff of $>2 \mathrm{~mm}$ of intrauterine fluid. However, Carthy et al. (2014), who also adapted the ultrasound reproductive tract scoring method developed by Mee et al. (2009) and used it to assess risk factors for inferior uterine scores in Irish dairy cows, found a much higher prevalence $(29.8 \%)$ of uterine tract score $\geq 2$. This difference may be explained by the range in DIM at examination, which in that study was broad, ranging from 0 to $300+$ DIM; not surprisingly, the earliest DIM period assessed (0 to 14 DIM) had the highest mean uterine score of 2.97 (Carthy et al., 2014), making direct comparison with this study difficult. The prevalence of both PVD and UE was 3.5\% $(90 / 2,589)$ between 25 and 49 DIM in the present study, and as far as we are aware, this has not been stated in any other previous published work. Dubuc et al. (2010a) found that the prevalence of both cytological endometritis $(\geq 6 \%$ PMN) and PVD ( $\geq$ mucopurulent) was $5.8 \%$ $(61 / 1,044)$ at 35 DIM, which was higher than the present study but was likely due to the poor sensitivity of ultrasound to identify cytological endometritis, a fact that has been noted by others (Barlund et al., 2008).

The shared risk factors across all 4 models were DIM at time of examination, the interaction between DIM at examination and RFM, twinning, and a cow's inferior PTA for calving interval. The effect of DIM was significant in this study; the earlier the PBE was performed, the higher the likelihood of testing positive with either method alone or both in combination. This finding has been noted by others (Griffin et al., 1974; Gautam et al., 2010; Giuliodori et al., 2017), and it is most likely because of the high clinical self-cure rates that tend to be seen in cows with RTD; some publications report clinical self-cure rates ranging from 57 to $77 \%$ (Dubuc et al., 2010b; Gautam et al., 2010; Giuliodori et al., 2013; Giuliodori et al., 2017). This apparent self-cure may be a true complete cure or a change to the subclinical state. This clinical self-cure rate also depends on the time at first diagnosis and the severity of the condition; those with higher scores have lower odds of self-cure or medical cure following treatment (Burke et al., 2010; Giuliodori et al., 2017).

Retained fetal membranes are a well-established risk factor for RTD (Kim and Kang 2003; Potter et al., 2010). Their presence delays involution and restoration of the endometrium, as well as maintaining the patency of the cervix, facilitating an entry point and a suitable environment for bacterial overgrowth (Sheldon et al., 2008). In the present study, the apparent prevalence of RFM was $1.8 \%$, which is lower than expected when compared with the prevalence of $4.06 \%$ (Mee, 1991) and more recently $2.3 \%$ (Buckley et al., 2007) found by others studying Irish grazing herds; this finding may have been due to inefficient recording. Despite the likely under-reporting, the significant interaction between RFM and DIM found in all models in the present study is an interesting finding. This interaction suggests that the probability of a positive diagnosis by either Metricheck or ultrasound is much higher in a cow who has RFM when examined early in milk than if she is examined later, when the probability of a positive diagnosis converges with that of a cow without RFM (Figure 2). This stresses the importance - especially in compact calving grazing systems - of targeting examinations earlier in milk to those who have RFM, particularly if these cows are also later calving and do not have the same amount of time to recover before breeding commences.

Twinning is a well-established risk factor for the development of RTD (Bell and Roberts, 2007; Dubuc et al., 2010b) and was significant across all 4 models. Twinning likely contributes to RTD through increased risk of assistance or dystocia (Mee et al., 2011), RFM (Nielen et al., 1989), and metabolic issues (Markusfeld, 1987; Nishida et al., 1997). Knowledge of twinning as a risk factor is important not only to identify cows that are more at risk of contracting RTD but also to implement preventative measures to mitigate that risk. Diligent monitoring and skilled assistance at calving (Mee, 2004), early dry-off due to shortened gestation (Nielen et al., 1989), and minimizing BCS loss in this cohort over the dry period (Bell and Roberts 2007) have been suggested and may play a role in reducing RTD in this cohort of cows.

The predicted transmitting ability or the genetic value for calving interval that will be transmitted to the cow's offspring was associated with RTD across all 
4 models. Cows with higher values for calving interval had greater odds of being diagnosed with RTD, regardless of the diagnostic method. Heritability estimates for RTD are generally low and vary across populations from 0.02 to 0.03 in Irish and Canadian cows (Koeck et al., 2012; Carthy et al., 2015) to 0.07 in the United States (Zwald et al., 2004). Interestingly, Carthy et al. (2015) and Fitzgerald et al. (2014), both using a similar ultrasound scoring system, found that an inferior uterine environment was associated with traditional reproductive traits such as calving interval, and that selection for superior genetic merit for the traditional reproductive traits was associated with favorable outcomes in these traits; this study supports those findings. To our knowledge, this is the first time the association has been shown for PVD in an Irish context, but this should not be surprising, because others have reported that estimates for the different assessments of RTD (metritis, PVD, and endometritis) are similar, and the genetic correlations between them do not differ (Koeck et al., 2012).

Some authors have described a quadratic association between parity and RTD; primiparous cows and cows in their third lactation or greater are more likely to develop metritis than cows in their second lactation. (Markusfeld, 1984; Gröhn et al., 1990; Bruun et al., 2002). This finding was supported by the present study in model 1 , which found that primiparous cows were at higher odds of PVD than multiparous cows, as noted by others (Potter et al., 2010; Giuliodori et al., 2017.) Model 2 showed that older cows ( $\geq$ fifth lactation) were at greater risk of having UE, a finding that has also been described by others (Carthy et al., 2014). Model 3 showed this quadratic association, because both parity groups were at risk when either PVD or UE was considered RTD. Primiparous cows are more likely to develop dystocia and genital tract damage as a result (Meyer et al., 2001; Mee et al., 2011). This genital tract damage likely results in impaired cervical patency and resultant bacterial colonization of the uterus; however, it is certainly possible that in a proportion of these cases the PVD originates from cervical or anterior vaginal inflammation and not endometrial inflammation, a conclusion shared by others (Deguillaume et al., 2012). This may help to explain why primiparae are at greater risk of PVD and not UE, as seen in this study. Others have found that endometritis and ultrasound tract scoring deteriorates by parity number (Kim and Kang 2003; Carthy et al., 2014), as seen in the present study, and may be explained by poor vulval angle (Potter et al., 2010), urovagina (Gautam and Nakao, 2009), and impaired bacterial clearance in older cows $(\geq$ fifth lactation; Gilbert et al., 1993) which are all risk factors for RTD.
Calving difficulty score $(\geq 3)$ was a significant risk factor for PVD alone (model 1) and PVD or UE (model 3 ), but not for UE alone (model 2) or a combination of PVD and UE (model 4). The finding of assisted calvings or dystocia as a risk factor for PVD was not surprising and has been reported by many others (Dubuc et al., 2010b; Potter et al., 2010; Giuliodori et al., 2013, 2017). As in the present study, there have been conflicting reports about the association between dystocia and UE or subclinical endometritis. Carthy et al. (2014) found that cows with dystocia in their previous calving had inferior ultrasonographic uterine scores, in contrast to this study. However, Dubuc et al. (2010b) and Cheong et al. (2011) both failed to find dystocia as a risk factor for subclinical endometritis, more in agreement with the present study.

Breed was a significant risk factor for PVD alone (model 1) and PVD or UE (model 3), but not for UE alone (model 2) or a combination of PVD and UE (model 4). In both models 1 and 3, Holstein Friesian cows were at greater risk of having PVD alone or a combination of PVD or UE than Jersey cows, in contrast to other studies in grazing cows, which found no difference (McDougall et al., 2007; Carthy et al., 2014). More interesting, however, was the interaction we observed between calving difficulty and breed, indicating that a Jersey cow with a difficult calving (score $\geq 3$ ) had a much greater likelihood of developing endometritis than a Holstein Friesian cow with a difficult calving. This interaction seems to imply that when difficult calvings occur in Jerseys, these cows are more likely to experience genital tract trauma, inflammation, and endometritis as a result. More focused efforts, such as careful sire selection and early dystocia intervention, may help to reduce RTD in this cohort.

Cows who gave birth to beef-sired calves were at increased risk of UE in model 2, but not in the other models. A wide array of AI and stock bull sire breeds were used on farms in this study, from dairy breeds (Holstein Friesian and Jersey) to continental beef breeds (Charolais, Limousin, and Belgian Blue) and early-maturing beef breeds (Angus and Hereford), and were broadly categorized as beef or dairy sires. Mee et al. (2011) has shown that the likelihood of calving assistance or dystocia was greater for males sired by Charolais sires in Holstein Friesian cows in Ireland, and this may explain why beef-sired calves play a role in increasing the odds of developing UE seen in cows in this study. Use of a stock bull was significant in the univariable analysis, but not in any final multivariable model. In this study, only $5 \%$ of AI sires were beef breeds, and $66 \%$ of stock bull calves born were from beef sires. Because the use of beef stock bulls allows farmers to produce crossbred calves whose carcasses are more valuable than those 
of purebred dairy calves once replacements are bred (Wolfová et al. 2007), this finding would imply that use of easier-calving beef stock bulls may help reduce the incidence of UE.

Thinner cows $(\mathrm{BCS}<2.75)$ at $\mathrm{PBE}$ had greater odds of PVD than cows with ideal BCS in model 1, but not in the other models. This thinner group of cows most likely included 2 subsets: those that had lost excessive condition post-calving, and those that were thin at calving. This finding indicates the role that peripartum negative energy balance likely plays in the development of RTD. This finding has also been reported by others with high prepartum fatty acids and high postpartum BHB (Dubuc et al., 2010b; Cheong et al., 2011; Giuliodori et al., 2013), BCS loss post-calving (Giuliodori et al., 2017), and low BCS at calving (Hoedemaker et al., 2009; Dubuc et al., 2010b), all having being shown to increase the odds of PVD and subclinical endometritis. It should be noted that we found a trend for fat cows (BCS >3.5) at calving to be at higher risk of RTD in our study, but this was not seen in the final multivariable models and may have been due to a lack of statistical power in the models because of the low overall prevalence of fat cows at calving in our study.

The absence of a corpus luteum at PBE increased the risk of UE (model 2) and PVD or UE (model 3), and a similar pattern has been found by others (Senosy et al., 2009). Bacterial contamination of the endometrium is associated with reduced function of the dominant ovarian follicle (Sheldon et al., 2002; Williams et al., 2007) and delayed resumption of cyclicity (Opsomer et al., 2000), which may explain this finding. However, we found a significant interaction between DIM and the presence of a corpus luteum at PBE in both models (Supplemental Figure S1; https://doi.org/10.3168/jds .2019-17064). The interaction implied that cows with a corpus luteum present and examined at approximately <37 DIM (model 2) and <32 DIM (model 3) had a higher likelihood of a positive diagnosis than those without a corpus luteum (Supplemental Figure S2). However, beyond approximately 32 to 37 DIM, the presence of a corpus luteum at $\mathrm{PBE}$ reduced the likelihood of a positive diagnosis (Supplemental Figure S2). Some have reported that cows with an early resumption of cyclicity (before 21 DIM) had lower odds of subclinical endometritis at 49 DIM than cows that had not resumed cyclicity by 49 DIM (Galvão et al., 2010). Others have found that ovulatory status before the diagnosis of subclinical endometritis (at 42 DIM) was not a risk factor, but that cows with a prolonged resumption of cyclicity (>56 DIM) were more likely to have endometritis as a preceding condition (Burke et al., 2010). In the present study, reproductive exams were taken at different time points in each cow, corpus luteum status and diagnosis of RTD were determined at PBE, and the earliest exam took place at 25 DIM. Therefore, it was not possible to determine whether early ovulation status influenced the risk of developing endometritis, even though cows with a corpus luteum at $<35$ DIM appeared to have a higher predicted probability of a positive diagnosis. Likewise, is it not possible to say if these cows would have tested positive if examined later in milk. However, it is possible to infer that cows with no evidence of cyclical or estrus activity $>42$ DIM have higher odds of a positive diagnosis of UE and should be targeted for examination and intervention in seasonal calving systems, a finding noted by others (McDougall et al., 2007).

Many risk factors for RTD are well established, and a broad selection of these risk factors were tested in this study. Previously important risk factors such as calf sex (Potter et al., 2010) and stillbirth (Markusfeld, 1984; Potter et al., 2010) were not found to be significant. In a UK study on Holstein Friesian cows in an indoor system (Potter et al., 2010), the birth of a male calves was a risk factor for PVD, but in our study, male sex appeared to have no effect. One potential reason for this could be that our study lacked sufficient statistical power. However, we conducted a post hoc power simulation based on the differences noted for calf sex stated by Potter et al. (2010). From this analysis we found that given the effect of male sex noted in that study population, our statistical power was 0.91 given our sample size.

In the same study (Potter et al., 2010), stillbirth was also significant in the final model, and although stillbirth was significant on the univariate analysis in our study, it was not significant in any final multivariable models. This finding may have been due to differences in definitions of stillbirth (dead or alive at birth versus dead within $24 \mathrm{~h}$ ), or that our study was underpowered. In this case, we calculated a power of 0.71 for stillbirth based on our post hoc power analysis. This finding may also have been due to the fact that dystocia and stillborn risk in the UK has been attributed to "holsteinization" (McGuirk et al., 1999), which may not be as profound in Ireland, or even that some have found stillbirth in Holstein Friesian primiparae in Ireland to be increasingly unrelated to dystocia (Mee, 2006). All of this emphasizes the importance of testing and validating different risk factors in diverse cow populations.

Peripartum disease conditions such as metritis (Dubuc et al., 2010b), ketosis (Dubuc et al., 2010b), and hypocalcemia (Whiteford and Sheldon et al., 2005), which have all have been shown to be risk factors for RTD, were not tested in this study and cannot be ruled 
out as important risk factors. These will require future evaluation in future studies into RTD in grazing Irish dairy cows.

\section{CONCLUSIONS}

Even though PVD and UE are imperfect diagnostic tests, they remain the most practical cow-side options for RTD. Both methods of diagnosis share many common cow-level risk factors, which include DIM at PBE, RFM, twins, and cow genetics. Other risk factors that are specific to other diagnostic methods are considerable calving difficulty, parity, BCS, dam or sire breed, and the cow's cyclical activity. This may be because these diagnostic methods detect different manifestations of RTD in some instances. However, because both PVD and UE in isolation have been shown to have detrimental effects on subsequent reproductive performance, all of these findings should be considered for preventative advice and identifying at-risk cows.

\section{ACKNOWLEDGMENTS}

The authors thank the farmers in the UCD Kildare Group for their help and assistance with the collection and collation of fertility data.

\section{REFERENCES}

Barlund, C. S., T. D. Carruthers, C. L. Waldner, and C. W. Palmer. 2008. A comparison of diagnostic techniques for postpartum endometritis in dairy cattle. Theriogenology 69:714-723.

Bell, M. J., and D. J. Roberts. 2007. The impact of uterine infection on a dairy cow's performance. Theriogenology 68:1074-1079.

Bruun, J., A. K. Ersboll, and L. Alban. 2002. Risk factors for metritis in Danish dairy cows. Prev. Vet. Med. 54:179-190.

Buckley, F., P. Dillon, and J. F. Mee. 2007. Major management factors associated with the variation in reproductive performance of Irish dairy herds. Teagasc, Moorepark Dairy Production Research Centre, Fermoy, Co. Cork, Ireland. Accessed May 13, 2019. https: //t-stor.teagasc.ie/handle/11019/1003.

Burke, C. R., S. Meier, S. McDougall, C. Compton, M. Mitchell, and J. R. Roche. 2010. Relationships between endometritis and metabolic state during the transition period in pasture-grazed dairy cows. J. Dairy Sci. 93:5363-5373.

Carthy, T. R., D. P. Berry, A. Fitzgerald, S. McParland, E. J. Williams, S. T. Butler, A. R. Cromie, and D. Ryan. 2014. Risk factors associated with detailed reproductive phenotypes in dairy and beef cows. Animal 8:695-703.

Carthy, T. R., D. P. Ryan, A. M. Fitzgerald, R. D. Evans, and D. P. Berry. 2015. Genetic parameters of ovarian and uterine reproductive traits in dairy cows. J. Dairy Sci. 98:4095-4106.

Carthy, T. R., D. P. Ryan, A. M. Fitzgerald, R. D. Evans, and D. P. Berry. 2016. Genetic relationships between detailed reproductive traits and performance traits in Holstein-Friesian dairy cattle. J. Dairy Sci. 99:1286-1297.

Cheong, S. H., D. V. Nydam, K. N. Galvão, B. M. Crosier, and R. O. Gilbert. 2011. Cow-level and herd-level risk factors for subclinical endometritis in lactating Holstein cows. J. Dairy Sci. 94:762-770.

de Boer, M. W., S. J. LeBlanc, J. Dubuc, S. Meier, W. Heuwieser, S. Arlt, R. O. Gilbert, and S. McDougall. 2014. Invited review: Sys- tematic review of diagnostic tests for reproductive-tract infection and inflammation in dairy cows. J. Dairy Sci. 97:3983-3999.

Deguillaume, L., A. Geffré, L. Desquilbet, A. Dizien, S. Thoumire, C. Vornière, F. Constant, R. Fournier, and S. Chastant-Maillard. 2012. Effect of endocervical inflammation on days to conception in dairy cows. J. Dairy Sci. 95:1776-1783.

Dubuc, J., T. F. Duffield, K. E. Leslie, J. S. Walton, and S. J. LeBlanc. 2010a. Definitions and diagnosis of postpartum endometritis in dairy cows. J. Dairy Sci. 93:5225-5233.

Dubuc, J., T. F. Duffield, K. E. Leslie, J. S. Walton, and S. J. LeBlanc. 2010b. Risk factors for postpartum uterine diseases in dairy cows. J. Dairy Sci. 93:5764-5771.

Edmonson, A. J., I. J. Lean, L. D. Weaver, T. Farver, and G. Webster. 1989. A body condition scoring chart for Holstein dairy cows. J. Dairy Sci. 72:68-78.

Fitzgerald, A. M., D. P. Ryan, T. R. Carthy, R. D. Evans, and D. P. Berry. 2014. Ovarian structures and uterine environment are associated with phenotypic and genetic merit for performance in lactating dairy cows. Theriogenology 82:1231-1240.

Galvão, K. N., M. Frajblat, W. R. Butler, S. B. Brittin, C. L. Guard, and R. O. Gilbert. 2010. Effect of early postpartum ovulation on fertility in dairy cows. Reprod. Domest. Anim. 45:e207-e211.

Gautam, G., and T. Nakao. 2009. Prevalence of urovagina and its effects on reproductive performance in Holstein cows. Theriogenology 71:1451-1461.

Gautam, G., T. Nakao, K. Koike, S. T. Long, M. Yusuf, R. M. S. B. K. Ranasinghe, and A. Hayashi. 2010. Spontaneous recovery or persistence of postpartum endometritis and risk factors for its persistence in Holstein cows. Theriogenology 73:168-179.

Ghanem, M., A. H. Shalaby, S. Sharawy, and N. Saleh. 2002. Factors leading to endometritis in dairy cows in Egypt with special reference to reproductive performance. J. Reprod. Dev. 48:371-375.

Gilbert, R. O., Y. T. Gröhn, P. M. Miller, and D. J. Hoffman. 1993. Effect of parity on periparturient neutrophil function in dairy cows. Vet. Immunol. Immunopathol. 36:75-82.

Gilbert, R. O., S. T. Shin, C. L. Guard, H. N. Erb, and M. Frajblat. 2005. Prevalence of endometritis and its effects on reproductive performance of dairy cows. Theriogenology 64:1879-1888.

Giuliodori, M. J., R. P. Magnasco, D. Becu-Villalobos, I. M. LacauMengido, C. A. Risco, and R. L. de la Sota. 2013. Clinical endometritis in an Argentinean herd of dairy cows: Risk factors and reproductive efficiency. J. Dairy Sci. 96:210-218.

Giuliodori, M. J., R. P. Magnasco, M. Magnasco, I. M. Lacau-Mengido, and R. L. de la Sota. 2017. Purulent vaginal discharge in grazing dairy cows: Risk factors, reproductive performance, and prostaglandin F2 $\alpha$ treatment. J. Dairy Sci. 100:3805-3815.

Griffin, J. F. T., P. J. Hartigan, and W. R. Nunn. 1974. Non-specific uterine infection and bovine fertility: I. Infection patterns and endometritis during the first seven weeks post-partum. Theriogenology 1:91-106.

Gröhn, Y., H. N. Erb, C. E. McCulloch, and H. S. Saloniemi. 1990. Epidemiology of reproductive disorders in dairy cattle: Associations among host characteristics, disease and production. Prev. Vet. Med. 8:25-39.

Herath, S., S. T. Lilly, D. P. Fischer, E. J. Williams, H. Dobson, C. E. Bryant, and I. M. Sheldon. 2009. Bacterial lipopolysaccharide induces an endocrine switch from prostaglandin F2alpha to prostaglandin E2 in bovine endometrium. Endocrinology 150:1912-1920.

Hoedemaker, M., D. Prange, and Y. Gundelach. 2009. Body condition change ante- and postpartum, health and reproductive performance in German Holstein cows. Reprod. Domest. Anim. 44:167173.

Kim, I.-H., and H.-G. Kang. 2003. Risk factors for postpartum endometritis and the effect of endometritis on reproductive performance in dairy cows in Korea. J. Reprod. Dev. 49:485-491.

Koeck, A., F. Miglior, D. F. Kelton, and F. S. Schenkel. 2012. Health recording in Canadian Holsteins: Data and genetic parameters. J. Dairy Sci. 95:4099-4108.

LeBlanc, S. J., T. F. Duffield, K. E. Leslie, K. G. Bateman, G. P. Keefe, J. S. Walton, and W. H. Johnson. 2002. Defining and di- 
agnosing postpartum clinical endometritis and its impact on reproductive performance in dairy cows. J. Dairy Sci. 85:2223-2236.

López-Helguera, I., F. López-Gatius, and I. Garcia-Ispierto. 2012. The influence of genital tract status in postpartum period on the subsequent reproductive performance in high producing dairy cows. Theriogenology 77:1334-1342.

Markusfeld, O. 1984. Factors responsible for post parturient metritis in dairy cattle. Vet. Rec. 114:539-542.

Markusfeld, O. 1987. Periparturient traits in seven high dairy herds. Incidence rates, association with parity, and interrelationships among traits. J. Dairy Sci. 70:158-166.

McDougall, S. 2001. Effects of periparturient diseases and conditions on the reproductive performance of New Zealand dairy cows. N. Z. Vet. J. 49:60-67.

McDougall, S., H. Hussein, D. Aberdein, K. Buckle, J. Roche, C. Burke, M. Mitchell, and S. Meier. 2011. Relationships between cytology, bacteriology and vaginal discharge scores and reproductive performance in dairy cattle. Theriogenology 76:229-240.

McDougall, S., R. Macaulay, and C. Compton. 2007. Association between endometritis diagnosis using a novel intravaginal device and reproductive performance in dairy cattle. Anim. Reprod. Sci. 99:9-23.

McGuirk, B. J., I. Going, and A. R. Gilmour. 1999. The genetic evaluation of UK Holstein Friesian sires for calving ease and related traits. Anim. Sci. 68:413-422.

Mee, J. F. 1991. The incidence of retained foetal membranes on nine dairy research farms over a ten year period (1978-1987). Ir. Vet. J. $44: 48-52$.

Mee, J. F. 2004. Managing the dairy cow at calving time. Vet. Clin. North Am. Food Anim. Pract. 20:521-546.

Mee, J. F. 2006. The unexplained stillbirth. Ir. Vet. J. 59:438-439.

Mee, J. F., D. P. Berry, and A. R. Cromie. 2011. Risk factors for calving assistance and dystocia in pasture-based Holstein Friesian heifers and cows in Ireland. Vet. J. 187:189-194.

Mee, J. F., F. Buckley, D. Ryan, and P. Dillon. 2009. Pre-breeding ovaro-uterine ultrasonography and its relationship with first service pregnancy rate in seasonal-calving dairy herds. Reprod. Domest. Anim. 44:331-337.

Meira, E. B. S., L. C. S. Henriques, L. R. M. Sá, and L. Gregory. 2012. Comparison of ultrasonography and histopathology for the diagnosis of endometritis in Holstein-Friesian cows. J. Dairy Sci. 95:6969-6973

Meyer, C. L., P. J. Berger, K. J. Koehler, J. R. Thompson, and C. G. Sattler. 2001. Phenotypic trends in incidence of stillbirth for Holsteins in the United States. J. Dairy Sci. 84:515-523.

Nielen, M., Y. H. Schukken, D. T. Scholl, H. J. Wilbrink, and A. Brand. 1989. Twinning in dairy cattle: A study of risk factors and effects. Theriogenology 32:845-862.

Nishida, T., M. Kurihara, F. Terada, and M. Shibata. 1997. Energy requirements of pregnant Holstein dairy cows carrying single or twin Japanese black fetuses in late pregnancy. Anim. Sci. Technol. 68:572-578.

Opsomer, G., Y. T. Gröhn, J. Hertl, M. Coryn, H. Deluyker, and A. de Kruif. 2000. Risk factors for post partum ovarian dysfunction in high producing dairy cows in Belgium: A field study. Theriogenology 53:841-857.

Potter, T. J., J. Guitian, J. Fishwick, P. J. Gordon, and I. M. Sheldon. 2010. Risk factors for clinical endometritis in postpartum dairy cattle. Theriogenology 74:127-134.

R Core Team. 2015. R: A Language and Environment for Statistical Computing. R Foundation for Statistical Computing, Vienna, Austria.

Šavc, M., M. Duane, L. E. O'Grady, J. R. Somers, and M. E. Beltman. 2016. Uterine disease and its effect on subsequent reproductive performance of dairy cattle: A comparison of two cow-side diagnostic methods. Theriogenology 86:1983-1988.

Senosy, W. S., M. Uchiza, N. Tameoka, Y. Izaike, and T. Osawa. 2009. Association between evaluation of the reproductive tract by various diagnostic tests and restoration of ovarian cyclicity in highproducing dairy cows. Theriogenology 72:1153-1162.

Sheldon, I. M., J. Cronin, L. Goetze, G. Donofrio, and H.-J. Schuberth. 2009. Defining postpartum uterine disease and the mechanisms of infection and immunity in the female reproductive tract in cattle. Biol. Reprod. 81:1025-1032.

Sheldon, I. M., G. S. Lewis, S. LeBlanc, and R. O. Gilbert. 2006. Defining post-partum uterine disease in cattle. Theriogenology 65:1516-1530

Sheldon, I. M., D. E. Noakes, A. N. Rycroft, D. U. Pfeiffer, and H. Dobson. 2002. Influence of uterine bacterial contamination after parturition on ovarian dominant follicle selection and follicle growth and function in cattle. Reproduction 123:837-845.

Sheldon, I. M., E. J. Williams, A. N. A. Miller, D. M. Nash, and S. Herath. 2008. Uterine diseases in cattle after parturition. Vet. J. 176:115-121.

Whiteford, L. C., and I. M. Sheldon. 2005. Association between clinical hypocalcaemia and postpartum endometritis. Vet. Rec. 157:202.

Williams, E. J., D. P. Fischer, D. E. Noakes, G. C. W. England, A. Rycroft, H. Dobson, and I. M. Sheldon. 2007. The relationship between uterine pathogen growth density and ovarian function in the postpartum dairy cow. Theriogenology 68:549-559.

Williams, E. J., D. P. Fischer, D. U. Pfeiffer, G. C. W. England, D. E. Noakes, H. Dobson, and I. M. Sheldon. 2005. Clinical evaluation of postpartum vaginal mucus reflects uterine bacterial infection and the immune response in cattle. Theriogenology 63:102-117.

Wolfová, M., J. Wolf, J. Kvapilík, and J. Kica. 2007. Selection for profit in cattle: II. Economic weights for dairy and beef sires in crossbreeding systems. J. Dairy Sci. 90:2456-2467.

Zwald, N. R., K. A. Weigel, Y. M. Chang, R. D. Welper, and J. S. Clay. 2004. Genetic selection for health traits using producerrecorded data. I. Incidence rates, heritability estimates, and sire breeding values. J. Dairy Sci. 87:4287-4294.

\section{ORCIDS}

E. Kelly (i) https://orcid.org/0000-0001-5145-860X

C. G. McAloon ( ) https://orcid.org/0000-0002-4984-4031

M. E. Beltman (ํ) https://orcid.org/0000-0002-1598-4845 